Jpn. J. Med. Sci. Biol., 45, 127 - 136, 1992.

\title{
A VERTICALLY TRANSMITTED HIV-1 GAG-SUBTYPE VARIANT DETECTED IN TAIWAN
}

\author{
Hong-Guang GUO and Kenneth Shueh-Shen CHANG1*
}

Laboratory of Tumor Cell Biology, National Cancer Institute, National Institutes of Health, Bethesda, MD 20892, USA and 1Graduate Institute of Clinical Medicine, Chang Gung Medical College, Taoyuan, Taiwan, Republic of China

(Received June 15, 1992. Accepted August 31, 1992)

SUMMARY: We used polymerase chain reaction (PCR) to amplify a segment, about 560 base pairs (bp), of HIV-1 gag DNA prepared from peripheral blood mononuclear cells of a seropositive Taiwanese pair of mother and infant. TM-1 and TC-1 clones of PCR-amplified DNA derived from the mother and infant, respectively, showed a $94.5 \%$ homology with each other. However, the TM-1 and TC-1 sequences exhibited lower degrees of homology, i.e. only $85.1 \%$ and $85.8 \%$, respectively, with the corresponding gag segment of a North American HIV-1 subtype (HXB2), and $86.4 \%$ and $87.0 \%$, respectively, with that of a Zairean HIV-1 subtype (Z2Z6). The divergence of TM-1 and TC-1 sequences from those of HXB2 and Z2Z6 is particularly prominent in the first (5' proximal) $200 \mathrm{bp}$ of the cloned DNA segment, involving transitions more frequently than transversions. Two additional clones TM-2 and TC-2 derived from the mother and infant were sequenced for the first $200 \mathrm{bp}$. These four clones showed a high degree of homology (94.7-97.5\%) among themselves, providing an evidence for transmission of the virus from the mother to the infant. These findings show the epidemiological value of PCR, and indicate the presence of a gag subtype of HIV-1 which is distinct from both the North American and Zairean subtypes according to the phylogenetic tree constructed.

*Reprints requests to Dr. Kenneth S. S. Chang, Graduate Institute of Clinical Medicine, Chang Gung Medical College, Taoyuan, Taiwan, Republic of China. 


\section{INTRODUCTION}

Genetic variants of human immunodeficiency virus type 1 (HIV-1) arise during viral replication by error-prone reverse transcription $(1,2)$. From an infected individual, different isolates may exhibit high degrees of variability $(3,4)$. The complex mixture of quasispecies $(5,6)$ in an infected individual may lead to selection of a variant on the basis of high replication efficiency with different degrees of cytopathic effects (7-9), specific cellular tropism (10-13) or capability to escape from the immunologic defense mechanisms (14-16). Most of these variabilities are reflected as changes in env gene sequences. In contrast, the gag sequence is more conserved among different isolates of HIV-1 (17).

Perinatal transmission of HIV-1 is estimated to occur in 13-39\% of infants born to infected mothers (18-20). The polymerase chain reaction (PCR) for detection of HIV-1 genome in these infants would be a more accurate diagnostic measure of infection than the HIV-1 antibody tests, since the maternal antibody in the peripheral blood of an uninfected infant may give a false positive test. We have cloned the gag sequences amplified by PCR from the DNA of the peripheral blood mononuclear cells obtained from a Taiwanese mother and her infant daughter who were both found to be seropositive for HIV-1 infection (21). The cloned gag sequences from them were found to be closely related to each other, and thus strongly suggest that the infant was infected through vertical transmission from her mother. While gag DNA sequences obtained from some other seropositive Taiwanese individuals were closely related to those of North American HIV-1 subtype (unpublished data), those derived from the mother-child pair were, unexpectedly, quite distinct from known North American and Zairean subtypes. Their phylogenetic relationships are presented in this report.

\section{MATERIALS AND METHODS}

Blood specimens: A heparinized peripheral blood sample was collected in April, 1989 from a 25-year old Taiwanese woman with a persistent lymphadenopathy, and from her infant daughter (6-month old), who were both found to be seropositive (confirmed by Western blot) for HIV-1 in December, 1988. The woman had lived with a man of German nationality who is now suspected to be a bisexual. He has left her since, and is not available for test. The high 
molecular weight DNA was extracted from the mononuclear cells which were separated from erythrocytes by Ficoll-Hypaque method.

PCR-amplification, cloning and sequencing: DNA samples $(2 \mu \mathrm{g})$ were subjected to repeated rounds of amplification (30 cycles) in a $100-\mu 1$ reaction mixture containing $100 \mathrm{pmol}$ each of SK37 primer (26-mer sense strand: ATACAGTAGCAACCCTCTATTGTGTG) and SK39 primer (28-mer antisense strand: TTTGGTCCTTGTCTTATGTCCAGAATGC) (22), [nucleotides 1027 to 1052 and 1657 to 1630 , respectively, of the $\mathrm{HXB2}$ sequence (17)], $200 \mu \mathrm{M}$ each deoxynucleotide, $50 \mathrm{mM} \mathrm{KCl}, 10 \mathrm{mM}$ Tris (pH 8.3), $1.5 \mathrm{mM} \mathrm{MgCl}_{2}$, and $2 \mathrm{U}$ of Taq DNA polymerase. Each cycle consisted of a 2-min denaturation step at $94 \mathrm{C}$, followed by a 2-min annealing step at $50 \mathrm{C}$, and a 2-min extension at $72 \mathrm{C}$, except that the first cycle used a 5-min denaturation at $94 \mathrm{C}$, and the last cycle used a 7 -

min extension at $72 \mathrm{C}$. Aliquots $(5 \mu \mathrm{l})$ of the PCR mixture were mixed with $5 \mu \mathrm{l}$ of distilled water and $1 \mu \mathrm{l}$ of stop buffer, and electrophoresed on $0.8 \%$ agarose gels containing $0.5 \mu \mathrm{g}$ of ethidium bromide per $\mathrm{ml}$. After electrophoresis, gels were denatured, neutralized, and transferred to nylon membrane filters, which were then prehybridized by standard method and hybridized with 32P-labeled SK19 probe (22) (41-mer sense strand: ATCCTGGGATTAAATAAAATAGTAAGAATGTATAGCCCTAC) (nucleotides 1587 to 1627 of the HXB2 sequence). The filters were autoradiographed and if hybridization results were positive, the amplified DNA was cloned. The multiple cloning site of pBluescript $\Pi$ SK $+/-$ was cut with EcoRV and dephosphorylated before ligation with the PCRamplified fragments which were treated with polynucleotide kinase. The recombinant plasmid was used for transformation of $E$. coli HB101 and screened by colony-hybridization with SK19 probe. The positive colony was harvested and minipreparations were prepared for DNA sequencing by standard dideoxy method. All sequences were resolved on buffer gradient gels, and both plus- and negative-strands were sequenced.

\section{RESULTS AND DISCUSSION}

Two clones of the PCR-amplified gag fragment of DNA derived from the Taiwanese woman (TM-1 and TM-2) and two from her infant daughter (TC-1 and TC-2) were analyzed. As shown in Fig. 1, the sequences for TM-1 (563 bp) and TC$1(562 \mathrm{bp}$ ) were compared with the corresponding sequence (nucleotides 1066 to 1629) of the North American subtype, HXB2 (17,23), and that (nucleotides 1067 to 1633 ) of the Zairean subtype, Z2Z6 (17). It is evident that while TM-1 and TC-1 sequences were quite similar with each other, they showed quite a number of dissimilarities when compared with those of HXB2 and Z2Z6. These 
HXB2 1066

Z2Z6 1067

TM-1

TC-1

HXB2 1125

Z2z6 1127

TM-1 59

TC-1 59

HXB2 1183

Z2z6 1187

TM-1 118

TC-1 118

HXB2 1243

Z2Z6 1247

TM-1 177

TC-1 176

HXB2 1303

z2z6 1307

TM-1 237

TC-1 236

HXB2 1363

Z2Z6 1367

TM-1 299

TC-1 298

HXB2 1423

$\begin{array}{lll}22 \mathrm{Z} 6 & 1427\end{array}$

TM-1 357

TC-1 356

HXB2 1483

Z2Z6 1487

TM-1 417

TC-1 416

HXB2 1543

2226 1547

TM-1 477

TC-1 476

HXB2 1603

Z2Z6 1607

TM-1 537

TC-1 536

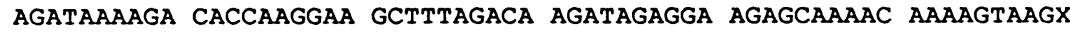

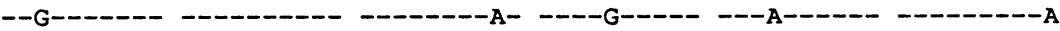

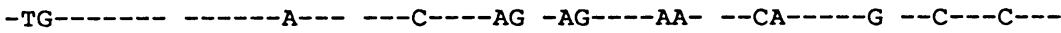

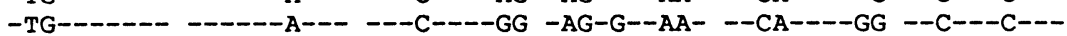

XXAAAAAAGC ACAGCAAGCA GCAGCTGACA CAGGACACAG CAATCAgGTC AgCCAAAATT AC-----G-- -------- -------G ----GA---A --GC----- - - - - - -

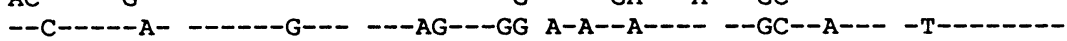
$--\mathrm{C}-----\mathrm{A}------\mathrm{G}------\mathrm{AG}---\mathrm{G}-\mathrm{A}----\mathrm{A}------\mathrm{GC}--\mathrm{A}----\mathrm{T}--------$

ACCCtatagt gCagaAcatc CaggggcaAa tggtacatca ggCCAtatca cCtagaActT

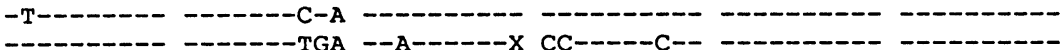

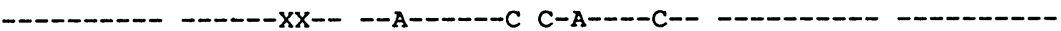

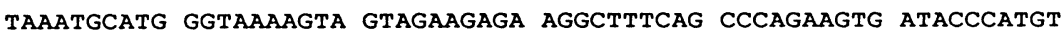
-G--C--- - - -

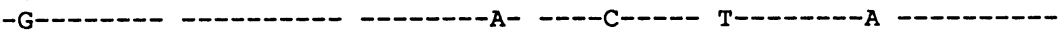

TTTCAGCATT ATCAGAAGG GCCACCCCAC AAGATTtAAA CACCATGCTA AACACAgtgG I

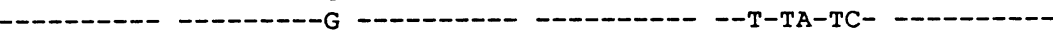

GGGGACATCA AGCAGCCATG CAAATGTTAA AAGAGACCAT CAATGAGGAA GTCGCAGAAT $-\mathrm{AA}-\mathrm{G}---------\mathrm{T}--\mathrm{A}-----\mathrm{C}---\mathrm{G}---\mathrm{T}--\mathrm{A}-------\mathrm{A}---\cdots----\mathrm{G}-$

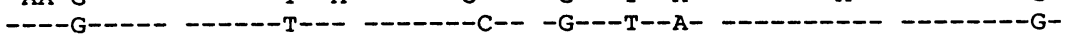

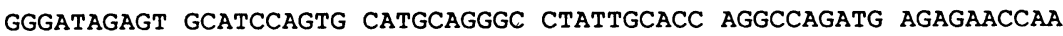
$\mathrm{A}---\mathrm{C}--\mathrm{GA}-\mathrm{A}-----\mathrm{CCA}--\mathrm{A}-------------\mathrm{T}----\mathrm{A}-\cdots-\mathrm{T}----$

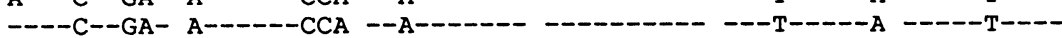

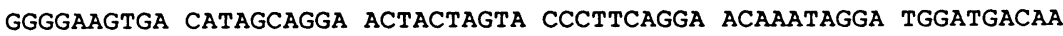
-A- ----1 T-A-

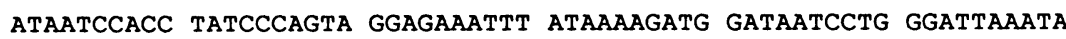
GC--C- - - - GC-

AAATAGTAAG AATGTATAGC CCTACCA

-------- --------- ---GT--

- - - - - - - - - - - - -

- - - - - - - - - - - - GTT-

Fig. 1. Nucleotide sequence alignments for HXB2, Z2Z6, TM-1 and TC1 gag sequences. - : identical to HXB2. X: a gap inserted to maintain alignment. 
dissimilarities were quite prominent in the segment representing the first (5' proximal) $200 \mathrm{bp}$. Therefore, two more clones, TM-2 and TC-2, derived also from the mother and her infant were sequenced for 199 and $200 \mathrm{bp}$, respectively, and compared with the corresponding segment of TM-1 and TC-1 sequences, as illustrated in Fig. 2. These sequences were quite similar with each other, giving 94.7-97.5\% homologies as compared among themselves. Therefore, these clones may represent a set of quasispecies present in each individual $(5,6)$. As reported by Goodenow et al. (5), these changes in nucleotides involved transitions more frequently than transversions. The close relatinoship between these four clones as shown by the high degree of homologies among themselves suggests strongly that the infant was infected with the vertically transmitted HIV-1 from her mother. Since the infant was delivered by cesarian section and bottle-fed (21), it is highly probable, but not proven, that intrauterine or intrapartum infection occurred. Since only a few clones were examined, it is difficult to say whether a selective transmission of a particular quasispecies from the mother to the infant occurred, as reported recently by Wolinsky et al (24). Nevertheless, it is evident that PCR-amplification and sequencing is valuable for epidemiological tracing of sources of HIV-1 infection. These gag sequences isolated from the mother-infant pair may represent defective viruses because of the deletions and mutations observed. The presence of such defective clones of quasispecies has also been described by others (5) although the significance of such defective viruses in the pathogenesis of AIDS is not clear.

The interrelationships in terms of homologies among TM-1, TC-1, HXB2 and Z2Z6 gag sequences are presented in Fig. 3. While TM-1 sequence showed a 94.7\% homology to that of TC-1, it exhibited lower similarities to those of HXB2 and Z2Z6, giving homologies of $85.1 \%$ and $86.4 \%$, respectively. TC-1 sequence also showed rather low homologies, i.e. $85.8 \%$ and $87.0 \%$, respectively, to those of HXB2 and Z2Z6. The HXB2 sequences showed a 93.7\% homology to that of Z2Z6, the former representing a North American subtype and the latter a Zairean subtype. As shown in Fig. 4, the phylogenetic tree which was constructed on the basis of our TC-1 sequence compared with a spectrum of other sequences (17), the TC-1 sequence stands out as the most distant cousin of BRU sequence which is quite similar to that of HXB2. In fact, the TC-1 sequence is not only distinct from the viruses BRU, HXB2, JH31, RF, OYI and JRCSF which would cluster as North American subtype, but also quite different from those of ELI, Z2Z6, NDK, and MAL viruses which would cluster as Zairean subtype. It is of interest to point out that the TC-1 sequence is positioned in the phylogenetic tree between the 


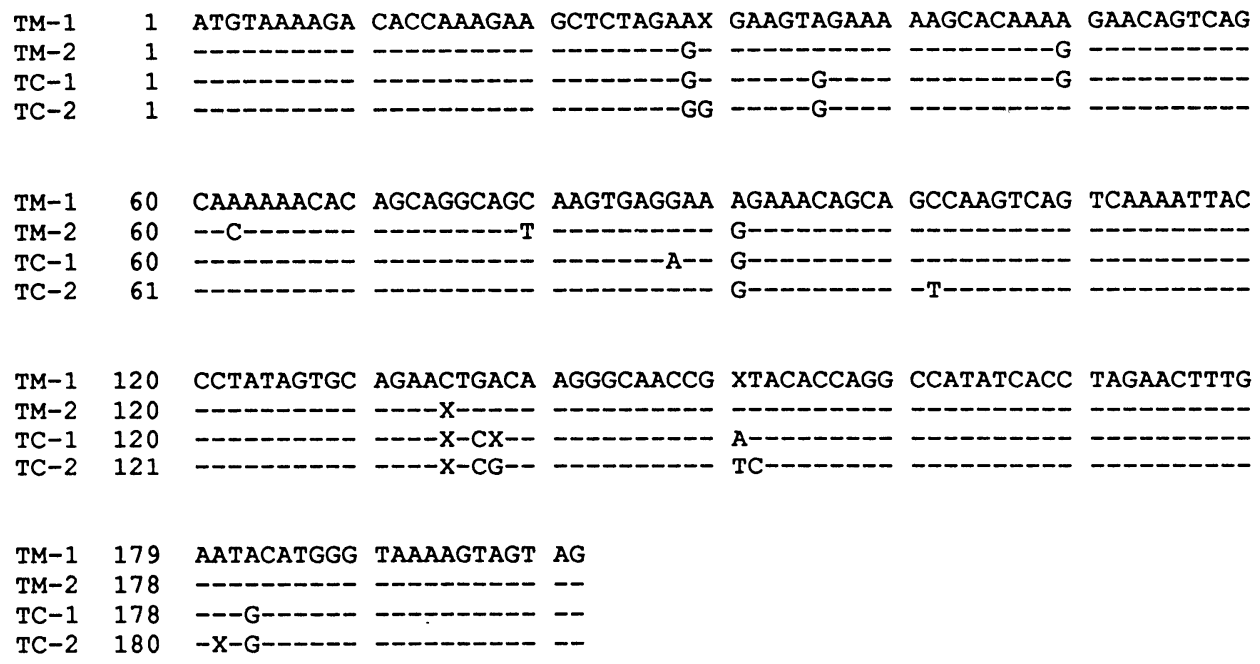

Fig. 2. Nucleotide sequence alignments for TM-1, TM-2, TC-1 and TC-2 gag sequences. - : identical to TM-1. X: a gap inserted to maintain alignment.

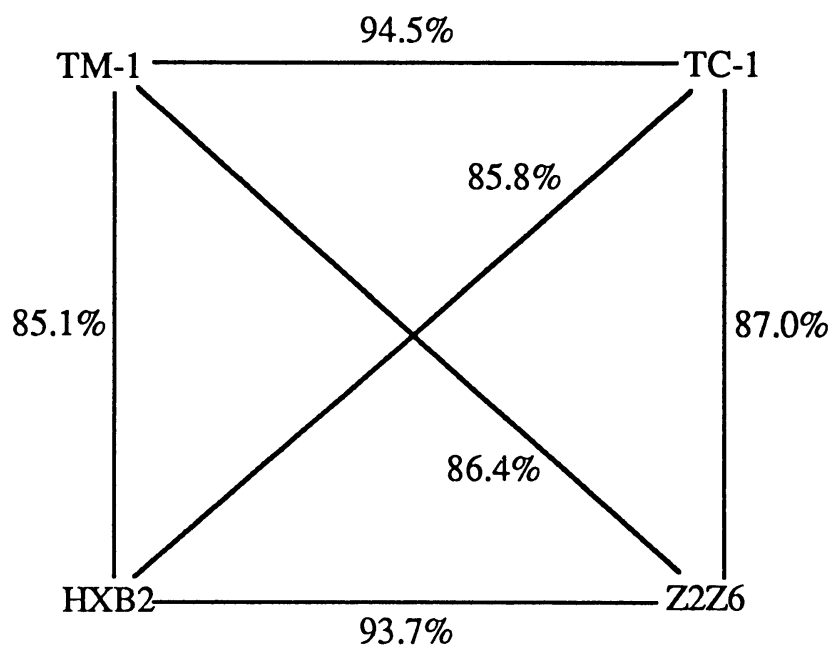

Fig. 3. Interrelationships in terms of degrees of similariteis among the gag sequences of TM-1, TC-1, HXB2 and Z2Z6. 
Total Sites: 585

Varied Sites: 213

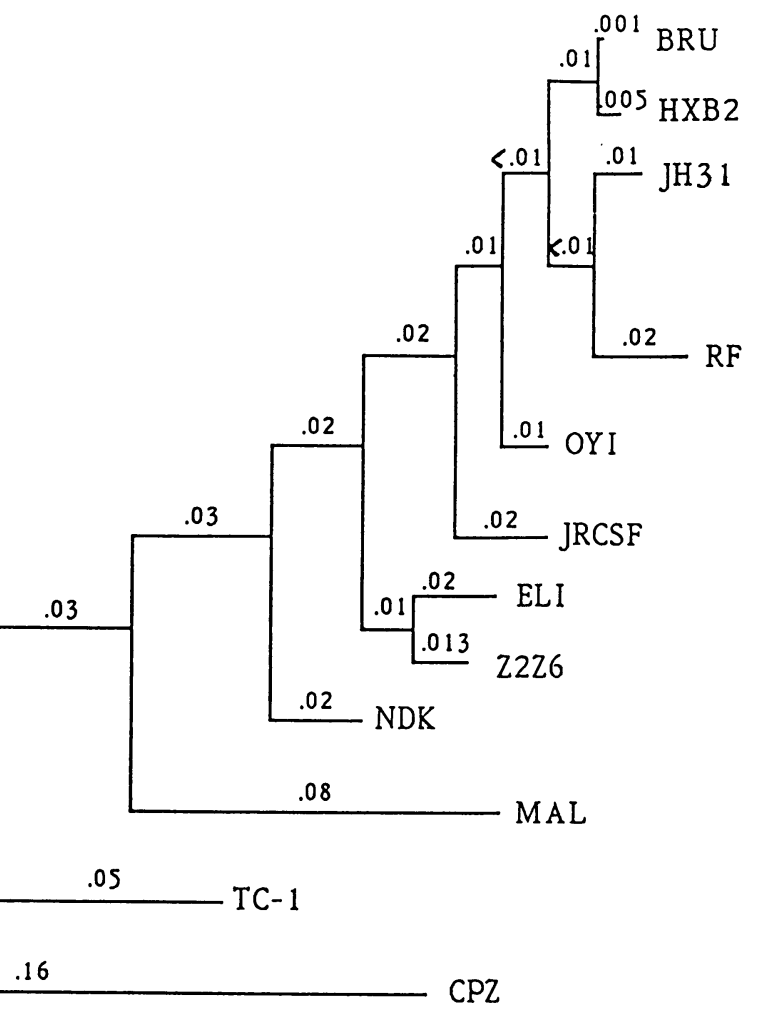

Fig. 4. Phylogenetic tree of HIV-1 gag sequences including TC-1 sequences. Sequences of BRU, HXB2, JH31, RF, OYI and JRCSF cluster as North American subtype, while ELI, Z2Z6, NDK, and MAL sequences are included in the Zairean subtype. CPZ, which is a simian immunodeficiency virus (SIV) isolated from a chimpanzee, is related to HIV-1. [See Ref. (17) for origins of these viruses.]

Zairean subtype and the CPZ virus, which is an HIV-1-like simian immunodeficiency virus (SIV) isolated from a chimpanzee $(17,25)$. Recently, it was proposed by G. Myers that, based on our TM-1 and TC-1 sequence supplied to the database, these (Taiwanese strains) would represent one of the five "families" of viruses (26). The other four "families" would include (i) US and European strains, (ii) Brazilian and Zairean strains, (iii) Zambian and Somalian strains, and (iv) the strains from Uganda, Ivory Coast and Kenya (26).

It may be speculated that the Taiwanese woman was infected from the man of German nationality who could have been the carrier of a distinct subtype of 
HIV-1. Unfortunately, this person and the Taiwanese mother-infant pair are not available for further study, and the amount of the original sample of DNA was not sufficient for further analysis of sequences other than gag. However, we are using portions of the known TM-1 and TC-1 sequences as primers and probes to determine the prevalence of this subtype of HIV-1 among various populations.

\section{AKNOWLEDGEMENTS}

Our thanks are due to Dr. C. Y. Chuang (Taiwan University College of Medicine) and Dr. Y. C. Ko (Kaohsiung Medical College) for providing the blood samples for these studies. We appreciate very much the advice of Dr. Marvin Reitz (National Cancer Institute, NIH) for this investigation.

\section{REFERENCES}

1. Roberts, J. D., Bebenek, K. and Kunkel, T. A. (1988): The accuracy of reverse transcriptase from HIV-1. Science, 242, 1171-1173.

2. Takeuchi, Y., Nagumo, T. and Hoshino, H. (1988): Low fidelity of cell-free DNA synthesis by reverse transcriptase of human immunodeficiency virus. J. Virol., 62, 3900-3902.

3. Saag, M. S., Hahn, B. H., Gibbons, J., Li, Y., Parks, E S., Parks, W. P. and Shaw, G. M. (1988): Extensive variation of human immunodeficiency virus type- 1 in vivo. Nature, $334,440-444$.

4. Hahn, B. H., Shaw, G. M., Taylor, M. E., Redfield, R. R., Markham, P. D., Salahuddin, S. Z., Wong-Staal, F., Gallo, R. C., Parks, E. S. and Parks, W. P. (1986): Genetic variation in HTLV-III/LAV over time in patients with AIDS or at risk for AIDS. Science, 232, 1548-1553.

5. Goodenow, M., Huet, T., Saurin, W., Kwok, S., Sninsky, J. and WainHobson, S. (1989): HIV-1 isolates are rapidly evolving quasispecies: evidence for viral mixtures and preferred nucleotide substitutions. J. AIDS, 2, 344-352.

6. Meyerhans, A., Cheynier, R., Albert, J., Seth, M., Kwok, S., Sninsky, J., Morfeldt-Manson, L., Asjö, B. and Wain-Hobson, S. (1989): Temporal fluctuations in HIV quasispecies in vivo are not reflected by sequential HIV isolations. Cell, 58, 901-910.

7. Fenyö, E. M., Morfeldt-Manson, L., Chiodi, F., Lind, B., von Gegerfelt, A., Albert, J., Olausson, E. and Asjo, B. S. (1988): Distinct replicative and 
cytopathic characteristics of human immunodeficiency virus isolates. J. Virol., 62, 4414-4419.

8. Rubsamen-Waigmann, H., Becker, W. B., Helm, E. B., Brodt, R., Fischer, H., Henco, K. and Brede, H. D. (1986): Isolation of variants of lymphocytopathic retroviruses from the peripheral blood and cerebrospinal fluid of patients with ARC or AIDS. J. Med. Virol., 19, 335-344.

9. McNearney, T., Westervelt, P., Thielan, B. J., Trowbridge, D. B., Garcia, J., Whittier, R. and Ratner, L. (1990): Limited sequence heterogeneity among biologically distinct human immunodeficiency virus type 1 isolates from individuals involved in a clustered infectious outbreak. Proc. Natl. Acad. Sci. USA, 87, 1917-1921.

10. Cheng-Mayer, C., Seto, D., Tateno, M. and Levy, J. A. (1988): Biologic features of HIV-1 that correlate with virulence in the host. Science, 240, 8082.

11. Sakai, K., Dewhurst, S. Ma, X. and Volsky, D. J. (1988): Differences in cytopathogenicity and host cell range among infectious molecular clones of human immunodeficiency virus type 1 simultaneously isolated from an individual. J. Virol., 62, 4078-4085.

12. Shioda, T., Levy, J. A. and Cheng-Mayer, C. (1991): Macrophage and T cellline tropisms of HIV-1 are determined by specific regions of the envelope gp120 gene. Nature, 349, 167-169.

13. Hwang, S. S., Boyle, T. J., Lyerly, H. K. and Cullen, B. R. (1991): Identification of the envelope V3 loop as the primary determinant of cell tropism in HIV-1. Science, 253, 71-74.

14. Phillips, R. E., Rowland-Jones, S., Nixon, D. F., Gotch, F. M., Edwards, J. P., Ogunleesi, A. O., Elvin, J. G., Rothbard, J. A., Bangham, C. R. M., Rizza, C. R. and McMichael, A. J. (1991): Human immunodeficiency virus genetic variation that can escape cytotoxic $T$ cell recognition. Nature, 354, 453-459.

15. Nara, P. L., Smit, L., Dunlop, N., Hatch, W., Merges, M., Waters, D., Kelliher, J., Gallo, R. C., Fischinger, P. J. and Goudsmit, J. (1990): Emergence of viruses resistant to neutralization by V3-specific antibodies in experimental human immunodeficiency virus type 1 IIIB infection of chimpanzees. J. Virol., 64, 3779-3791.

16. Broliden, P. A., Ljunggren, K., Hinkula, J., Norrby, E., Akerlblom, L. and Wahren, B. (1990): A monoclonal antibody to human immunodeficiency virus type 1 which mediates cellular cytotoxicity and neutralization. J. Virol. 64, 936-940.

17. Myers, G., Rabson, A. B., Berzofsky, J. A., Smith, T. F. and Wong-Staal, F. (eds.) (190): Human retroviruses and AIDS database. Theoretical Biology and Biophysics, Los Alamos National Laboratory, Los Alamos, NM, USA.

18. Katz, S. L. and Wilfert, C. M. (1989): Human immunodeficiency virus infection of newborns. New Engl. J. Med., 320, 1687-1689.

19. Ryder, R. W., Nsa, W., Hassig, S. E., Behets, F. Rayfield, M., Ekungola, B., Nelson, A. M., Mulenda, U., Francis, H., Mwandagalirwa, K., Davachi, F., 
Rogers, M., Nzilambi, N., Greenberg, A., Mann, J., Quinn, T. C., Piot, P. and Curran, J. W. (1989): Perinatal transmission of the human immunodeficiency virus type 1 to infants of seropositive women in Zaire. New Engl. J. Med., 320, 1637-1642.

20. Blanche, S., Rouzioux, C., Moscato, M.-L. G., Veber, F., Mayaux, M.-J., Jacomet, C., Tricore, J., Deville, A., Vial, M., Firtion, G., De Crepy, A., Douard, D., Robin, M., Courpotin, C., Ciraru-Vigneron, N., Le Deist, F., Griscelli, C. and HIV Infection in Newborns French Collaborative Study Group (1989): A prospective study of infants born to women seropositive for human immunodeficiency virus type 1. New Engl. J. Med., 320, 1643-1648.

21. Ko, Y.-C. and Chang, S.-J. (1990): Taiwan's first case of perinatal transmission of HIV confirmed by a modified Western blot test. Kaohsiung J. Med. Sci., 6, 517-522.

22. Ou, C.-Y., Kwok, S., Mitchell, S. W., Mack, D. H., Sninsky, J. J., Krebs, J. W., Feorino, P., Warfield, D. and Schochetman, G. (1988): DNA amplification for direct detection of HIV-1 in DNA of peripheral blood mononuclear cells. Science, 239, 295-297.

23. Ratner, L., Fisher, A., Jagodzinski, L. L., Mitsuya, H., Liou, R.-S., Gallo, R. C. and Wong-Staal, F. (1987): Complete nucleotide sequences of functional clones of the AIDS virus. AIDS Res Human Retroviruses., 3, 57-69.

24. Wolinsky, S. M., Wike, C. M., Korber, B. T. M., Hutto, C., Parks, W. P., Rosenblum, L. L., Kunstman, K. J., Furtado, M. R. and Munoz, J. L. (1992): Selective transmission of human immunodeficiency virus type-1 variants from mothers to infants. Science, 255, 1134-1137.

25. Huet, T., Cheynier, R., Meyerhans, A., Roelants, G. and Wain-Hobson, S. (1990): Genetic organization of a chimpanzee lentivirus related to HIV-1. Nature, 345, 356-359.

26. Sternberg, S. (1992): HIV comes in five family groups. Science, 256, 966. 